\title{
Genetic analysis of calving traits by the multi-trait individual animal model
}

\author{
J. I. Weller*1 and E. Ezra† \\ *Institute of Animal Sciences, ARO, The Volcani Center, Bet Dagan 50250, Israel \\ †Israel Cattle Breeders Association, Caesaria Industrial Park, Caesaria 38900, Israel
}

\begin{abstract}
Five alternative models were applied for analysis of dystocia and stillbirth in first and second parities. Models 1 and 2 were included only to estimate the parameters required for model 4 , and models 3 and 5 are included only as comparisons to the model 4 estimates. Variance components were estimated by multi-trait REML, including cows with valid calving records for both parities. For the effects of sire of calf on first and second parities, variance components were estimated including only calvings with the same sire of calf for both parities. All heritabilities for the cow effect were quite low, but higher for dystocia than for stillbirth and higher in first parity. The sire-of-calf heritabilities were higher than the cow effect heritabilities, except for stillbirth in parity 2. Unlike the effect of cow correlations, all sire of calf correlations were $>0.6$, and the correlations for the same trait in parities 1 and 2 were $>0.9$. Thus, a multi-trait analysis should yield a significant gain in accuracy with respect to the sire of calf effects for bulls not mated to virgin heifers. A multi-trait individual animal model algorithm was developed for joint analysis of dystocia and stillbirth in first and second parities. Relationships matrices were included both for the effects of cow and sire of calf. In addition, random herd-year-season and fixed sex of calf effects were included in the model. Records were preadjusted for calving month and age. A total of 899,223 Israeli Holstein cows with first calvings since 1985 were included in the complete analysis. Approximate reliabilities were computed for both sire of cow and sire of calf effects. Correlations between these reliabilities and reliabilities obtained by direct inversion of the coefficient matrix for a sire of cow-sire of calf model were all close to 0.99 . Phenotypic trends for cows born from 1983 through 2007 were economically unfavorable for dystocia and favorable for stillbirth in both parities. Genetic trends were economically unfavorable for
\end{abstract}

Received April 30, 2015.

Accepted September 15, 2015.

${ }^{1}$ Corresponding author: joel.weller@mail.huji.ac.il both dystocia and stillbirth in first parity. First-parity sire of calf trends were unfavorable for dystocia, but favorable for stillbirth. All environmental trends were nearly zero. Regressions of evaluations of the complete analysis on a model including only calvings before 2011 were all $>0.8$. All evaluations met the Interbull Method 3 criterion for unbiasedness. Model 4, which computed genetic evaluations for all animals for all 4 traits accounting for all known relationships and correlations among the traits, is recommended for routine genetic evaluation of calving traits.

Key words: dairy cattle, multi-trait animal model, dystocia, stillbirth, Israeli Holsteins

\section{INTRODUCTION}

Both dystocia or difficult calving (DC) and stillbirth (SB) affect the profitability of dairy production. The DC reduces the productive life of the cow and decreases the probability of survival of the calf. The DC on firstparity calvings reduced herd-life of Israeli Holsteins by $\sim 180 \mathrm{~d}$ (Weller and Ezra, 2015). Despite the economic value of both traits, genetic evaluation is problematic because both traits are categorical, rather than continuous, and both have low heritability. In addition, incidence of both DC and SB are considerably higher for first-parity calvings, and genetic correlations among parities are incomplete (e. g., Liu et al., 2012). Finally, for both traits the phenotype is determined both by the cow calving and the sire of the calf (SC). Correlations between these 2 effects are at best minimal, and may even be antagonistic (Weller et al., 1988; Weller and Gianola, 1989). The effect of the cow calving can only be controlled genetically by inclusion of these traits in a selection index, whereas the SC effect can be controlled by a selective mating program. A selective mating plan for virgin heifers to reduce incidence of these traits was introduced in Israel in the 1960s (Bar-Anan et al., 1976). One-year-old sires are mated to first-parity cows; therefore, SC effects of these bulls can only be evaluated based on second-parity calvings. Only sires that have completed a progeny test and returned to general service are mated to virgin heifers. Until the 
year 2000, each bull returned to general service was mated to $\sim 1,000$ heifers. Based on the SC evaluations of these bulls for first-parity calving traits, only bulls with economically positive evaluations were selected to mate with the remaining heifers. For the last $15 \mathrm{yr}$, among the bulls returned to general service, bulls used to mate to virgin heifers were selected based on the $\mathrm{SC}$ evaluations of these bulls from the second-parity calvings of the cows mated to these bulls when they were 1 yr old.

Because of the discrete nature of the records, various studies have proposed analysis by threshold models, which assume the existence of an underlying normal variable that is responsible for the observed discrete observations (Djemali et al., 1987; Weller et al., 1988; Berger, 1994). Genetic evaluations for DC were first computed in the United States in 1977 (Van Tassell et al., 2003). A sire-maternal grandsire (MGS) threshold model, in which calvings for all parities were considered to be the same trait, was introduced for DC in 2003 (Van Tassell et al., 2003; Wiggans et al., 2003) and for SB in 2006 (Cole et al., 2007a,b). Cue and Hayes (1985) analyzed DC and SB jointly in a 2-trait sire model, but computed separate analyses for first and later parities, and separate analyses for the direct and maternal effects. Wiggans et al. (2008) proposed a multi-trait sire-MGS model in which first and later parities were analyzed as correlated traits; DC and SB were analyzed separately. They assumed that genetic correlations among later parities were equal to unity, although this assumption was not tested. Several studies have shown that DC and SB are correlated both phenotypically and genetically (Cue and Hayes, 1985; Ron et al., 1986; Weller et al., 1988; Weller and Gianola, 1989, Liu et al., 2012); thus, optimally, both traits should be analyzed jointly. Boelling et al. (2007) analyzed calving traits by a multi-trait sire-MGS model including DC, SB, and size of calf in first and later parities, but did not account for relationships.

The individual animal model (Westell and Van Vleck, 1987) came into commercial use during the late 1980s (e. g., Wiggans et al., 1988). The main advantages of the individual animal model are that all known relationships are included in the analysis, the model accounts for genetic merit of mates, and EBV are computed for all animals, not just sires with many progeny. Disadvantages are that computing time is much greater than sire models, reliabilities cannot be directly computed, and the model is generally amenable only to analysis of continuous traits. However, various studies have shown that loss in accuracy is generally minimal if dichotomous traits are analyzed by methods that assume a normal distribution of residuals (e.g., Weller et al., 1988). Jamrozik et al. (2005) analyzed Cana- dian Holsteins for 8 reproduction traits, including DC and SB by a multi-trait animal model (MAM), and estimated variance components by Bayesian methods with Gibbs sampling. However, only 53,158 cows were included in the analysis, and computing time was 1.5 mo. More recently, Van Pelt and De Jung (2011) analyzed SB by a MAM for Dutch Holsteins considering first and later parities as correlated traits. The DC was analyzed by a similar model (https://global.crv4all. com/68143/67761/67689/e14calease). Liu et al. (2012) analyzed DC and SB in first, second, and third parities of German Holsteins as 6 correlated traits by a MAM, with variance components estimated by a sire-MGS model.

In the age of genomics, derivation of EBV for all cows has an extra advantage, as many cow and calves are now routinely genotyped, and this data can be used to derive more accurate genomic EBV. In addition, because DC and SB are genetically correlated for both first and later parities, multi-trait analyses including both traits and first and later parities can use data from later parities to predict SC effects for matings to virgin calves. The objectives of our study were to estimate MAM maternal and SC (co)variance components for DC and SB for first and second parity, to develop a MAM algorithm for routine evaluation of these traits, and to compute phenotypic, genetic, and environmental trends for these traits.

\section{MATERIALS AND METHODS}

\section{Data}

First- and second-parity calvings of Israeli Holstein cows from January 1985 through May 2015 were analyzed. First-parity records were deleted if (1) SC or sire of cow was unknown, (2) days pregnant was listed as $<261$ or $>292 \mathrm{~d},(3)$ age at first calving was $<20$ or $>30$ mo, (4) sex of calf was not listed, or (5) calvings had multiple births. Second-parity records were deleted if no valid first-parity record was present. Both DC and SB were scored dichotomously. With respect to dystocia, farmers scored calvings according to 4 categories: unassisted, assisted but easy, assisted and difficult, or surgical. A calving was considered difficult if either of the last 2 categories was recorded. The SB was defined as birth of a dead calf, or death within $48 \mathrm{~h}$ of calving.

\section{Statistical Models}

The data were analyzed by 5 statistical models. Models 1 and 2 were used to estimate variance components for the analysis of all records by model 4 . Development and testing of model 4 was the main objective of the 
study. Models 3 and 5 were included only for comparison to the model 4 estimates.

Models 1 and 2 were analyzed by the REML MAM program MTC, developed by I. Misztal (University of Georgia, Athens). Model 1 included all cows with valid calving records for both parities born since 2005. (Due to software limitations, it was not possible to include the entire population in this analysis.) The analysis model was

$$
\begin{aligned}
\mathrm{Y}_{\mathrm{ijklmnop}}=\mathrm{a}_{\mathrm{ij}}+ & \mathrm{SC}_{\mathrm{ik}}+\mathrm{SC} 2_{\mathrm{il}}+\mathrm{HYS}_{\mathrm{im}}+\mathrm{G}_{\mathrm{in}} \\
& +\mathrm{C}_{\mathrm{io}}+\mathrm{e}_{\mathrm{ijklmnop}},
\end{aligned}
$$

where $\mathrm{Y}_{\mathrm{ijk} k m n o p}$ is the record of trait i (DC or SB in parity 1 or 2$)$; $\mathrm{a}_{\mathrm{ij}}$ is the additive genetic effect of cow $\mathrm{j}$ for trait $\mathrm{i} ; \mathrm{SC}_{\mathrm{ik}}$ is the effect of $\mathrm{SC} \mathrm{k}$ on trait i for parity 1 ; $\mathrm{SC} 2_{\mathrm{il}}$ is the effect of $\mathrm{SC} 1$ on trait i for parity $2 ; \mathrm{HYS}_{\mathrm{im}}$ is the effect of herd-year-season $\mathrm{m}$ for parity 1 on trait $\mathrm{i} ; \mathrm{G}_{\mathrm{in}}$ is the effect of sex of calf by parity $n$ on trait $\mathrm{i} ; \mathrm{C}_{\mathrm{io}}$ is the effect of first calving age o of the cow in months on trait $\mathrm{i}$; and $\mathrm{e}_{\mathrm{ijklmnop}}$ is the random residual associated with each record. The $\mathrm{G}$ and $\mathrm{C}$ effects were fixed, all other effects were random. The software requires that the levels of effects must be the same for all records on a specific animal; therefore, the effects of both firstand second-parity SC were included for each animal, and 4 sex-by-parity categories were defined, as given in Table 1. (Clearly, the effects of second-parity SC on first-parity calvings will be negligible.)

The number of records and levels of all effects are given in Table 1. All known parents and grandparents

Table 1. Number of records and levels of effects in the analyses

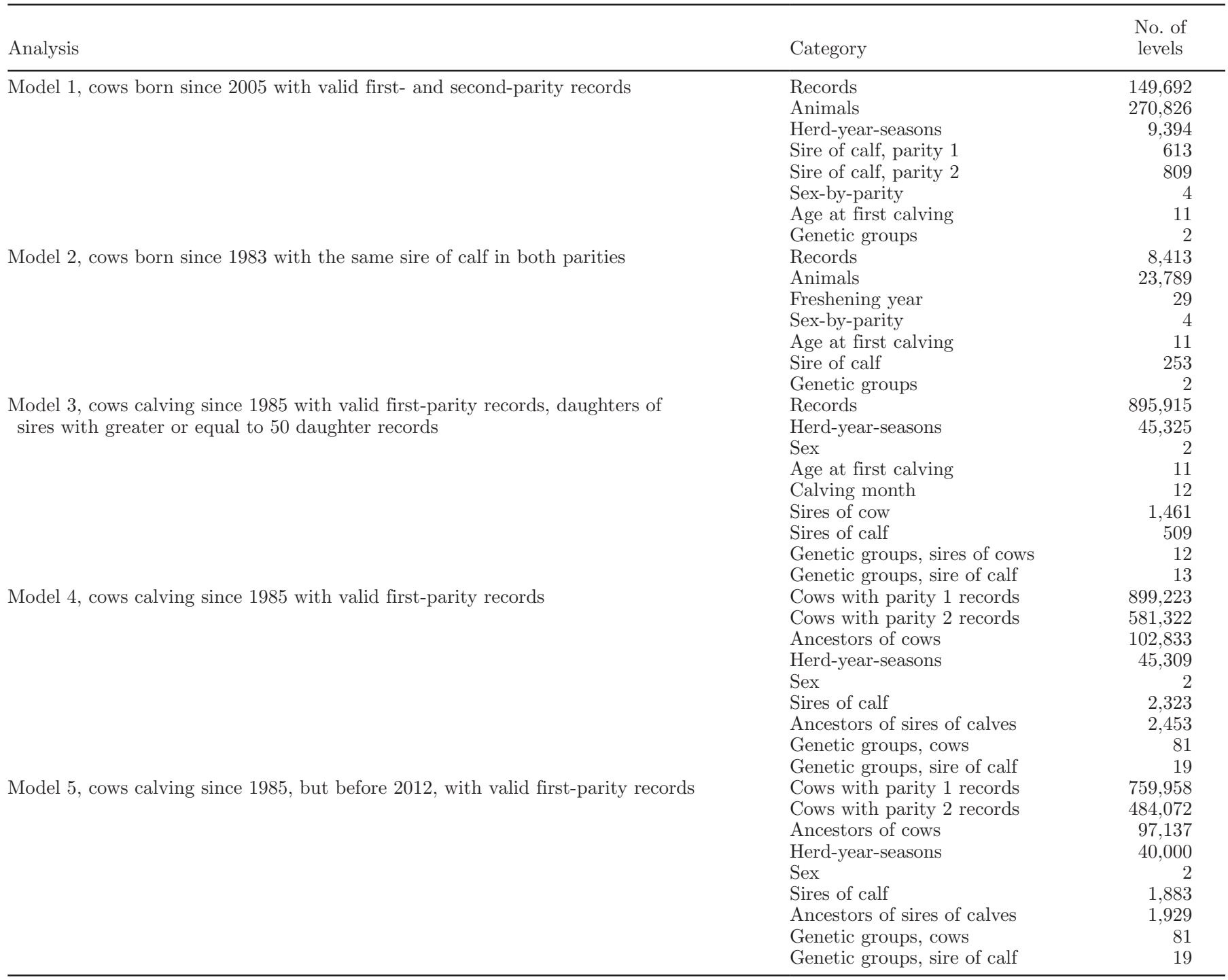


of cows with records were included in the relationship matrix for calculation of the cow additive genetic effect, thus the number of animals was nearly double the number of cows with records. Two genetic groups were defined for animals with unknown parents: one for males and one for females (Robinson, 1986). Two seasons were defined for each herd-year, beginning in April and October. There were 11 levels for the $\mathrm{C}$ effect (20 to $30 \mathrm{mo}$ of age at first calving). The number of levels for SC2 was greater than SC1, because, as noted previously, in the Israel breeding program, first-parity cows are generally mated to young, unproven bulls, whereas virgin heifers are mated only to bulls selected for general service.

The objective of model 2 was to estimate covariance components between first and second parities for the $\mathrm{SC}$ effect; thus, only cows with the same SC for both first and second parities were included in the analysis. This analysis included 8,413 cows born since 1983 that met the previous criterion. The analysis model was

$$
\mathrm{Y}_{\mathrm{ijklmno}}=\mathrm{a}_{\mathrm{ij}}+\mathrm{SC}_{\mathrm{ik}}+\mathrm{R}_{\mathrm{il}}+\mathrm{G}_{\mathrm{im}}+\mathrm{C}_{\mathrm{in}}+\mathrm{e}_{\mathrm{ijklmno}},
$$

where $\mathrm{SC}_{\mathrm{ik}}$ is the effect of $\mathrm{SC} \mathrm{k}$ for trait $\mathrm{i}$; $\mathrm{R}_{\mathrm{il}}$ is the effect of year of first calving 1 for trait $\mathrm{i}$; and the other terms are as defined for model 1 . As only a few cows in each herd-year-season (HYS) met the criterion of the same SC for both parities, the HYS effect was replaced by a fixed year of first calving effect. The numbers of levels of all effects are also given in Table 1. As in model 1, all parents and grandparents were included in the relationship matrix, and 2 groups were defined for animals with unknown parents. In this model, the number of ancestors was nearly double the number of cows with records, but only $253 \mathrm{SC}$ were included in the analysis.

Heritabilities for DC and SB were derived from model 1 as the additive genetic component of variance divided by the total variance, computed as the sum of the variances for the random effects. As in previous studies, heritabilities for the SC effects were computed from model 2 as 4 times the SC component of variance divided by the total variance.

Model 3 was the current sire of cow-SC model used for analysis of the entire population for first parity. This model included cows with valid first parity records calving since 1985. The DC and SB were analyzed separately. The analysis model was

$$
\begin{aligned}
\mathrm{Y}_{\mathrm{ijklmnopq}}= & \mathrm{S}_{\mathrm{ij}}+\mathrm{SC}_{\mathrm{ik}}+\mathrm{HYS}_{\mathrm{il}}+\mathrm{G}_{\mathrm{im}}+\mathrm{C}_{\mathrm{in}}+\mathrm{M}_{\mathrm{io}} \\
& +\mathrm{GS}_{\mathrm{ijp}}+\mathrm{GB}_{\mathrm{ikq}}+\mathrm{e}_{\mathrm{ijklmnopq}}
\end{aligned}
$$

where $S_{i j}$ is the effect of sire of cow $j$ on trait $i ; M_{i o}$ is the effect of calving month o for trait $\mathrm{i}$; $\mathrm{GS}_{\mathrm{ijp}}$ is the effect of sire-of-cow group p for sire $\mathrm{j}$; $\mathrm{GB}_{\mathrm{ikq}}$ is the effect of SC group q for SC k; and all other terms as defined previously. In this model the S, SC, HYS, and residuals effects were random and all other effects were fixed. Sires of cow and SC are nested within their respective groups, and the EBV are computed as the sum of the sire and group effects. This model was analyzed by the program CMMAT (I. Misztal) written for analysis of categorical data and solved by direct inversion of the coefficient matrix after absorption of the HYS effect. The HYS component of variance was assumed to be $10 \%$ of the residual variance for both DC and SB. The sire of calf and SC variance components were estimated by the REML option of CMMAT. To reduce the number of equations, HYS with $<2$ records, and sires of cows and SC with $<50$ records were deleted. Previous studies showed that reliabilities of bulls with $<50$ records are so low that these EBV are of no practical value. Reliabilities were derived from the diagonal elements of the inverse of the coefficient matrix as described by Weller et al. (1988).

Model 4 was the complete MAM analysis of the entire population and was solved by iteration. This model included all cows with valid first-parity records, first calving since 1985, and with calving records before June 2015. Four traits were analyzed: DC and SB in parities 1 and 2. Records were preadjusted for the effects of calving month and calving age. The analysis model was

$$
\begin{aligned}
\mathrm{Y}_{\mathrm{ijklmno}}=\mathrm{a}_{\mathrm{ij}} & +\mathrm{SC}_{\mathrm{ik}}+\mathrm{HYS}_{\mathrm{il}}+\mathrm{G}_{\mathrm{im}}+\mathrm{GS}_{\mathrm{ijn}} \\
& +\mathrm{GB}_{\mathrm{iko}}+\mathrm{e}_{\mathrm{ijklmno}},
\end{aligned}
$$

with all terms as defined previously. The HYS effect was random, and the HYS variance and covariance components derived from model 1 were applied. As covariances between first and second parities were assumed, HYS as in model 1 was defined relative to the first-parity calving. Unlike model $1, \mathrm{SC}$ and $\mathrm{G}$ effects were defined for each calving; thus, this model was able to accurately deal with the situation in which the SC was the same or different for cows with first- and second-parity calvings. In addition to the inverse of the relationship matrix for the cow effect, the inverse of the relationship matrix was also included for the SC effect, again including all parents and grandparents of sires of calves. The grouping strategy of Robinson (1986) was applied to define groups for individuals with unknown parents for both the additive genetic and SC effects. No covariances were assumed between the cow and SC effects. As noted in the introduction, this corresponds 
to previous studies that found that the correlations between the sire of cow and SC effects are minimal for both traits (e.g., Weller et al., 1988, Weller and Gianola, 1989).

The mixed model equations for this model are given in Figure 1, where $\mathbf{X}_{1}, \mathbf{X}_{2}, \mathbf{Z}_{1}$, and $\mathbf{Z}_{2}$ are the incidence matrices for the sex, HYS, and additive genetic and SC effects; $\mathbf{R}$ is the residual variance matrix for all records; $\mathbf{I}$ is an identity matrix; $\mathbf{H}$ is the $4 \times 4$ HYS variance matrix; $\mathbf{G}$ is the $4 \times 4$ additive genetic variance matrix; $\mathbf{D}$ is the $4 \times 4$ SC variance matrix; $\mathbf{A}$ is the numerator relationship matrix for the additive genetic effects; $\mathbf{B}$ is the numerator relationship matrix for the $\mathrm{SC} ; \otimes$ denotes the Kronecker matrix product; $\boldsymbol{\beta}_{1}, \boldsymbol{\beta}_{2}, \boldsymbol{\beta}_{3}, \boldsymbol{\beta}_{4}, \boldsymbol{\beta}_{5}$, and $\boldsymbol{\beta}_{6}$ are the solution vectors; and $\mathbf{y}$ is the vectors of records. $\mathbf{R}$ is a block diagonal matrix, thus $\mathbf{R}^{-1}=\mathbf{I} \otimes \mathbf{R}_{\mathrm{d}}^{-1}$, where $\mathbf{R}_{\mathrm{d}}$ is the $4 \times 4$ diagonal block of $\mathrm{R}$. For cows with records for both traits, $\mathbf{R}_{\mathrm{d}}$ is the $4 \times 4$ residual variance matrix. For cows with only first-parity records, only the $2 \times 2$ elements of the residual variance matrix referring to first parity records are nonzero. $\mathbf{A}$ was partitioned into $\mathbf{A}_{11}, \mathbf{A}_{12}, \mathbf{A}_{21}$, and $\mathbf{A}_{22}$ for relationships among animals with records, between animals with and without records and the transpose, and among animals without records. Similarly, $\mathbf{B}$ was partitioned into $\mathbf{B}_{11}$, $\mathbf{B}_{12}, \mathbf{B}_{21}$, and $\mathbf{B}_{22}$. The values of $\mathbf{G}, \mathbf{H}$, and $\mathbf{R}_{\mathrm{d}}$ were derived from model 1, whereas $\mathbf{D}$ was derived from model 2 .

The numbers of levels of all effects are given in Table 1. As nearly all milk-recorded cows with first calving since 1985 were included in the analysis, the number of ancestors without records was only $11 \%$ of the number of cows with records. However, the number of ancestors of SC was double the number of SC because both male and female ancestors were included. A total of 81 groups were defined for the additive genetic effect and 19 groups for the SC effect. Groups were determined by the sex and birth year of the animal with unknown parents and which parents were unknown: sire, dam, or both. Although $\sim 99 \%$ of the animals in the analysis were purebred Holsteins, a small fraction of cows were inseminated by bulls of other breeds. Separate groups by breed were determined for animals of other breeds.

Model 5 was the same as model 4, except that calving records were truncated $4 \mathrm{yr}$ previously, as proposed by Interbull for validation of EBV by Method 3; that is, all calvings after May 2011 were deleted. The number of levels of effects for model 5 is also given in Table 1 . The objective of this analysis was to test for bias of EBV of young versus old animals, as required by Interbull for validation of genetic evaluation methodologies.

\section{Iteration Methods and Estimation of reliabiLities}

As 4 equations were used for each level of effects included in the model 4 , the total number of equations was over 4 million. Iteration for models 4 and 5 was by Gauss-Seidel. In preliminary runs block iteration was used for all effects with the block consisting of the 4 traits for each level of each effect; however, convergence was not obtained with this algorithm. Reasonable convergence was obtained by an algorithm based on block iteration for the additive genetic effect, and row iteration for all other effects. Iteration was continued for 10,000 rounds, and convergence was monitored by comparison of the actual right-hand-sides to the regenerated right-hand-sides computed by multiplication of the coefficient matrix by the values of $\boldsymbol{\beta}$ derived by iteration.

Approximate reliabilities for sires of cows were computed from the following equation:

$$
r p t_{S i}=100\left\{\sigma_{g i}^{2}-\frac{4}{\left[n_{d} / \sigma_{e i}^{2}+16 /\left(3 \sigma_{g i}^{2}\right)\right]}\right\} / \sigma_{g i}^{2},
$$

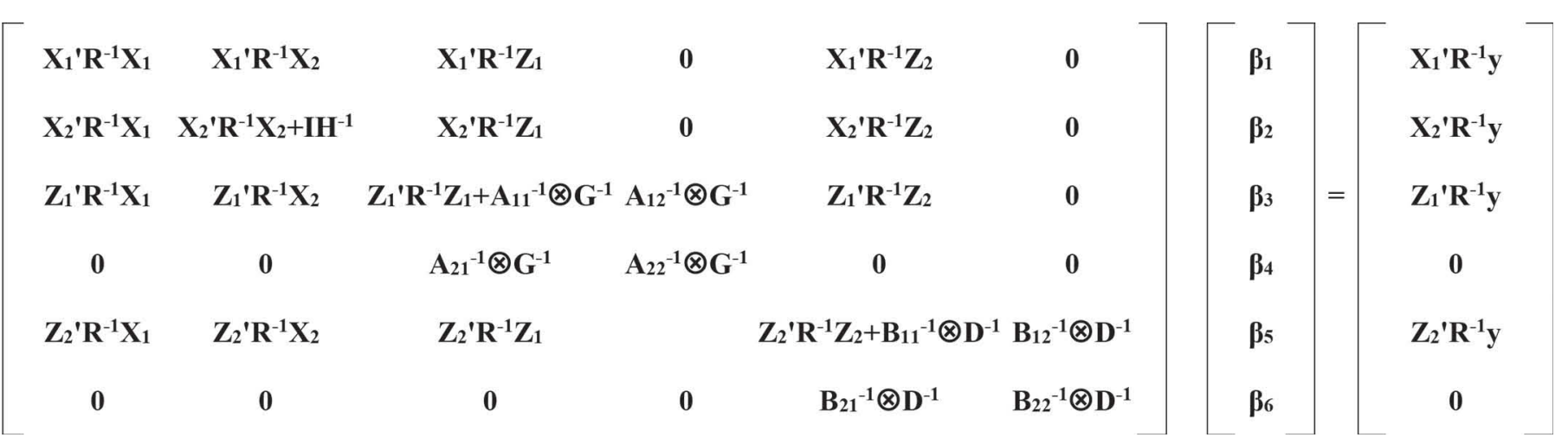

Figure 1. The mixed model equations for the model 4 analysis. All symbols are defined in the text. 
where $r p t_{S i}$ is the reliability of sire $\mathrm{S}$ for trait $\mathrm{i} ; \sigma_{g i}^{2}$ is the genetic variance for trait $i$; $n_{d}$ is the number of daughters with records for sire $\mathrm{S}$; and $\sigma_{e i}^{2}$ is the residual variance for trait $i$. This equation takes in account both relationships among animals and differences in the number of daughters per sire, with $n_{d}=0, r p t_{S i}=25$. Similarly for the SC effect reliabilities were estimated as follows:

$$
r p t_{S C i}=100\left\{\sigma_{S C i}^{2}-\frac{1}{\left[n_{S C} / \sigma_{e i}^{2}+4 /\left(3 \sigma_{S C i}^{2}\right)\right]}\right\} / \sigma_{S C i}^{2},
$$

where $r p t_{S C i}$ is the reliability for sire of calf SC for trait $\mathrm{i} ; \sigma_{S C i}^{2}$ is the SC variance for trait $\mathrm{i} ; n_{S C}$ is the number of calves sired by sire of calf SC; and $\sigma_{e i}^{2}$ is as defined previously. The algorithm of Misztal and Wiggans (1988), used to compute approximate reliabilities for the individual animal model, was also tested but failed to converge, apparently due to the very low heritabilities for calving traits (I. Misztal, personal communication).

\section{Analysis of EBV}

Estimated breeding value for the additive genetic effects were computed for all animals included in the analyses of models 4 and 5 for all 4 traits. In addition, EBV were computed for the SC effect for all bulls and their ancestors included in both analyses. The genetic base of the cow effect was the mean of cows born in 2005, and the genetic base for the SC effect was the mean of SC EBV of cows calving in 2005. Model 4 phenotypic trends were computed as the regression of the records for the 4 traits on the birthdates of the cows with records. Similarly, genetic trends were computed as the regression of the EBV of the cows on their birthdates, and SC trends were computed as the regression of the SC effect for each calf on the calves' calving dates. Environmental trends were estimated as the difference between the phenotypic trends and the sum of the genetic and SC trends.

Correlations among EBV for the 4 traits were computed for cows with records on both traits and for sires of cows and SC. First-parity model 4 EBV were compared with the model $3 \mathrm{EBV}$, and model 4 first-parity estimated reliabilities were compared with the model 3 reliabilities determined by coefficient matrix inversion. Model 4 and 5 EBV both for sires of calves and SC were compared for bulls born since 2005. In addition, Interbull Method 3 validation was applied for both the sire of cow and SC EBV for both traits for both parities (Boichard et al., 1995) based on local bulls born between 2002 and 2006, except for sire of cow in second parity. For sire of cow in second parity, bulls born between 2001 and 2005 were analyzed because bulls are $1 \mathrm{yr}$ older at their daughters' second calvings. In this method, the model 4 EBV were regressed on the model $5 \mathrm{EBV}$ according to the following equation:

$$
\mathrm{EBV}_{4 \mathrm{i}}=\alpha+\beta \times \mathrm{EBV}_{5 \mathrm{i}}+\delta \times \mathrm{t}_{\mathrm{i}}+\mathrm{e}_{\mathrm{i}},
$$

where $\mathrm{EBV}_{4 \mathrm{i}}$ and $\mathrm{EBV}_{5 \mathrm{i}}$ are the model 4 and $5 \mathrm{EBV}$ for bull $i$, respectively; $t_{i}$ is a function of the number of new births between 2011 and 2015 for sire i; $\alpha, \beta$, and $\delta$ are regression coefficients; and $\mathrm{e}_{\mathrm{i}}$ is the residual. For traits with moderate heritabilities analyzed in large populations, the EBV are considered unbiased if the absolute value of $\delta<0.02 \times \sigma_{\mathrm{g}}$, where $\sigma_{\mathrm{g}}$ is the genetic standard deviation. However, if the population was relatively small or heritability was low, the estimate of $\delta$ can be $>0.02 \times \sigma_{\mathrm{g}}$, even if $\delta$ was not significantly different from zero $(P<0.05)$. In this case, the EBV are considered unbiased if $\delta$ is not significantly different from zero (Weller et al., 2003).

Finally, model 4 and 5 SC evaluations were compared for 17 bulls with less than 5 first-parity calvings and at least 50 second-parity calvings in the model 5 data set and at least 40 first-parity calvings in the model 4 data set. The objective was to determine the ability of second-parity EBV to predict first-parity EBV for the SC effect.

\section{RESULTS AND DISCUSSION}

The REML estimates of variance components for model 1 (in \%) for DC and SB are given in Table 2. Genetic variance components were smaller than the HYS components, but both were small relative to the residual variance components. The parity 1 HYS variance for DC was $7 \%$ of the residual variance, but much smaller for SB and for both traits in second parity. All residual covariance components were positive, but the genetic covariance between DC and SB in second parity as well as the covariance between DC on parity 1 and SB on parity 2 and between SB on parity 1 and DC on parity 2 were slightly negative. Likewise, the covariance between the HYS effects for DC on parity 1 and SB on parity 2 was negative.

Heritability estimates and genetic and environmental correlations derived from model 1 are given in Table 3 . Similar to previous studies, all heritabilities were quite low, but higher for DC than for SB, and higher in first parity. Weller et al. (1988) found first-parity heritabili- 
Table 2. The REML estimates of variance components for model $1(\%)^{1}$

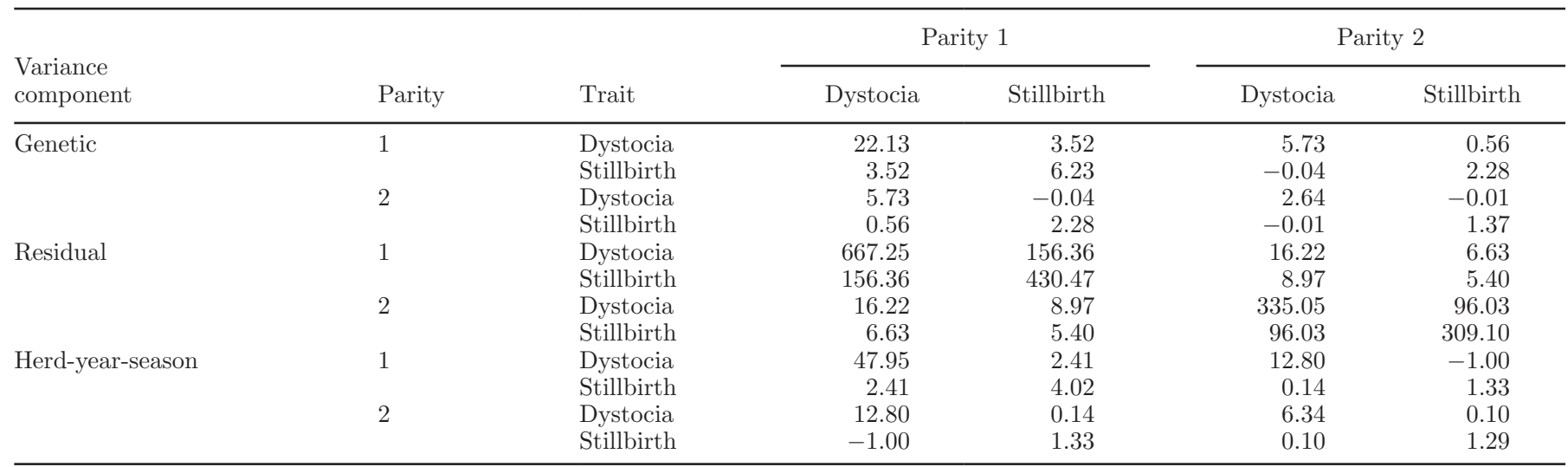

${ }^{1}$ The analysis included all cows born since 2005 with valid first- and second-parity records.

ties for DC of 0.139 and 0.063 by threshold and linear models, respectively, for Israeli Holsteins. Corresponding heritabilities for SB were 0.071 and 0.031 ; heritabilities for later parities were 0.042 and 0.008 for DC by threshold and linear models, respectively. Jamrozik et al. (2005) found heritabilities of 0.138 and 0.035 for DC and SB in first parity, respectively, and 0.063 and 0.017 in later parities by Gibbs sampling. Boelling et al. (2007) found heritabilities of 0.06 of DC and 0.035 for SB on first parity and 0.03 and 0.01 on later parities, whereas Cue and Hayes (1985) found heritabilities of 0.038 and 0.018 for first parity and 0.010 and 0.002 for second parity, respectively. Cole et al. (2007b) found a heritability of $\sim 0.055$ for SB in US Holsteins, whereas Wiggans et al. (2008) found heritabilities of 0.078 and 0.069 for DC and SB in first parity and 0.03 and 0.004 in later parities, respectively. Wiggans et al. (2003) found a heritability of 0.039 for DC by a threshold model, but with parities 1 to 3 combined. Liu et al. (2012) estimated heritabilities of 0.039 and 0.010 for first- and second-parity DC, respectively, and 0.054 and 0.006 for SB with a sire-MGS model.

Despite the low heritabilities, genetic correlations between DC in parities 1 and 2 and SB in parities 1 and 2 were 0.75 and 0.78 , respectively; Liu et al. (2012) found 0.76 and 0.63 . All other genetic correlation were $<0.1$, except for the correlation between DC and SB in parity 1. Environmental correlations were $<0.1$, except for the correlations between DC and SB on the same parity, which were close to 0.3. Jamrozik et al. (2005) found correlations of 0.52 and 0.013 between DC and SB in first and later parities, respectively. Boelling et al. (2007) found genetic correlations of 0.6 between DC and SB in both parities, whereas Cue and Hayes (1985) found correlations of 0.8 in first parity and 0.5 in second parity, which are considerably higher than in the current study. Boelling et al. (2007) obtained values of 0.74 and 0.6 for DC and SB, respectively, which are slightly lower than the current values, whereas Wiggans et al. (2008) found correlations of 0.81 and 0.74 ; both of these previous studies combined records from later parities. Liu et al. (2012) found correlations of 0.71 and 0.60 between DC and SB in first and second parities, respectively.

The SC variance components (in \%), heritabilities, and correlations derived from the model 2 analysis are given in Table 4. The SC heritabilities were higher than the cow effect heritabilities derived from model 1 , except for SB in parity 2. Unlike the cow effect genetic correlations, all $\mathrm{SC}$ correlations were $>0.6$, and

Table 3. Heritability estimates and genetic and environmental correlations derived from model $1^{1}$

\begin{tabular}{llccrrr}
\hline \multirow{2}{*}{ Parity } & & \multicolumn{2}{c}{ Parity 1} & & \multicolumn{2}{c}{ Parity 2} \\
\cline { 3 - 4 } \cline { 6 - 7 } & Trait & Dystocia & Stillbirth & & Dystocia & Stillbirth \\
\hline 1 & Dystocia & $\mathbf{0 . 0 3 0}$ & 0.300 & & 0.749 & 0.101 \\
& Stillbirth & 0.285 & $\mathbf{0 . 0 1 4}$ & & -0.009 & 0.781 \\
2 & Dystocia & 0.070 & 0.023 & & $\mathbf{0 . 0 0 8}$ & -0.003 \\
& Stillbirth & 0.013 & 0.025 & & 0.294 & $\mathbf{0 . 0 0 4}$ \\
\hline
\end{tabular}

${ }^{1}$ Heritability estimates on the diagonal (bold), genetic correlations above the diagonal, and environmental correlations below the diagonal. Heritability for each trait was estimated as the additive genetic variance divided by the sum of the additive genetic, herd-year-season, and residual variance. The analysis included all cows born since 2005 with valid first- and second-parity records. 
Table 4. Sire of calf variance components in (\%) and correlations derived from the model 2 analysis ${ }^{1}$

\begin{tabular}{|c|c|c|c|c|c|c|}
\hline Item & Parity & Trait & \multicolumn{2}{|c|}{ Parity 1} & \multicolumn{2}{|c|}{ Parity 2} \\
\hline \multirow[t]{3}{*}{ Variance components } & 1 & Dystocia & 11.55 & 5.11 & 4.71 & 0.60 \\
\hline & 2 & Dystocia & 4.71 & 2.19 & 2.07 & 0.28 \\
\hline & & Stillbirth & 0.60 & 0.49 & 0.28 & 0.08 \\
\hline \multirow[t]{2}{*}{ Correlations $^{2}$} & 1 & Dystocia & 0.061 & 0.818 & 0.963 & 0.624 \\
\hline & & Stillbirth & & & & 0.001 \\
\hline
\end{tabular}

${ }^{1}$ Derived from the analysis of cows with the same sire of calf for both parities.

${ }^{2}$ The heritability of the sire of calf effects, computed as 4 times the sire of calf component of variance divided by the total variance, is given on the diagonal (bold).

the correlations for the same trait in parities 1 and 2 were $>0.9$. Thus, the multi-trait analysis should yield a significant gain in accuracy with respect to the SC effects. However, it should be noted that these variance components are based only on cows inseminated by the same sire in both parities, hardly a representative or random sample.

Weller et al. (1988) found first-parity heritabilities of the SC effect for DC of 0.098 and 0.031 by threshold and linear models, respectively, for Israeli Holsteins; corresponding heritabilities for SB were 0.084 and 0.027 . Heritabilities for later parities were 0.022 and 0.004 for DC by threshold and linear models, respectively. Jamrozik et al. (2005) found heritabilities of 0.078 and 0.016 for DC and SB in first parity, respectively, and 0.075 and 0.012 in later parities by Gibbs sampling. Boelling et al. (2007) found heritabilities of 0.08 and 0.05 for DC, respectively, and 0.04 and 0.01 for SB in first and later parities, whereas Cue and Hayes (1985) found heritabilities of 0.04 and 0.01 for DC and 0.013 and 0.001 for SB in first and later parities, respectively. Wiggans et al. (2008) found heritabilities of 0.06 and 0.03 for $\mathrm{DC}$ and 0.038 and 0.004 for SB in first and later parities, respectively. Wiggans et al. (2003) found a heritability of 0.072 for DC by a threshold model, but with parities 1 to 3 combined. Klassen et al. (1990) found heritabilities of 0.047 and 0.020 for the SC effect of DC using data sets that included parities 1 and 2 and parities 2 and 3, respectively. Liu et al. (2012) found heritabilities of 0.048 and 0.026 for DC for parities 1 and 2, respectively, and 0.027 and 0.008 for SB.

Jamrozik et al. (2005) found correlations of 0.39 and 0.20 between the SC effects of DC and SB in first and later parities, respectively, whereas Liu et al. (2012) found correlations of 0.74 and 0.83 between DC and CM in parities 1 and 2. Jamrozik et al., (2005) found correlations between first and later parities were 0.52 for DC and 0.38 for SB, respectively, whereas Liu et al., (2012) found 0.89 and 0.80. Correlations among the
SC variance components computed by Boelling et al. (2007) were all lower than in the current study, whereas Cue and Hayes (1985) found correlations of 0.8 between the 2 traits in both first and later parities. Wiggans et al. (2008) found genetic correlations of 0.79 and 0.83 between first and later parities for DC and SB, respectively, which are also lower than in the current study.

Phenotypic means and sex effects for first- and second-parity dystocia and SB from the model 4 analysis are given in Table 5. First parity incidence of DC was higher than SB, but in parity 2 incidence of SB was slightly higher than DC. Similarly, the effect of sex was greater for DC than SB in first parity, but nearly the same in second parity. Considering only the 581,322 cows with second-parity records, first-parity frequencies of DC and SB were lower by 1.3 and $1 \%$. This corresponds to the results of Weller and Ezra (2015) that cows with either syndrome in first parity are more likely to be culled before second parturition. This also indicates that the model 1 and 2 samples that included only cows with second-parity calvings are biased with respect to first parity.

Means of DC and SB in parities 1 and 2 by calving month are given in Figure 2. First-parity DC and SB were highest in winter and lowest in June; this may be due to slightly shorter pregnancies in the summer. Differences in second parity were minimal for both traits. Effects of calving age for first and second parities are given in Figures 3 and 4; both traits were highest for cows calving at 20 mo. After a small increase from 22 to $23 \mathrm{mo}$, DC continued to decreased up to $30 \mathrm{mo}$; SB decreased from 20 to 23 mo, and then remained nearly constant until 28 mo. For parity 2, DC increased with increase in calving age up to $43 \mathrm{mo}$, whereas SB was minimal for cows calving at age of $35 \mathrm{mo}$.

Means of DC and SB in parities 1 and 2 by birth year are given in Figure 5, genetic means of the cows' EBV by birth year are given in Figure 6, and means of SC EBV by calving year, weighted by the number of 


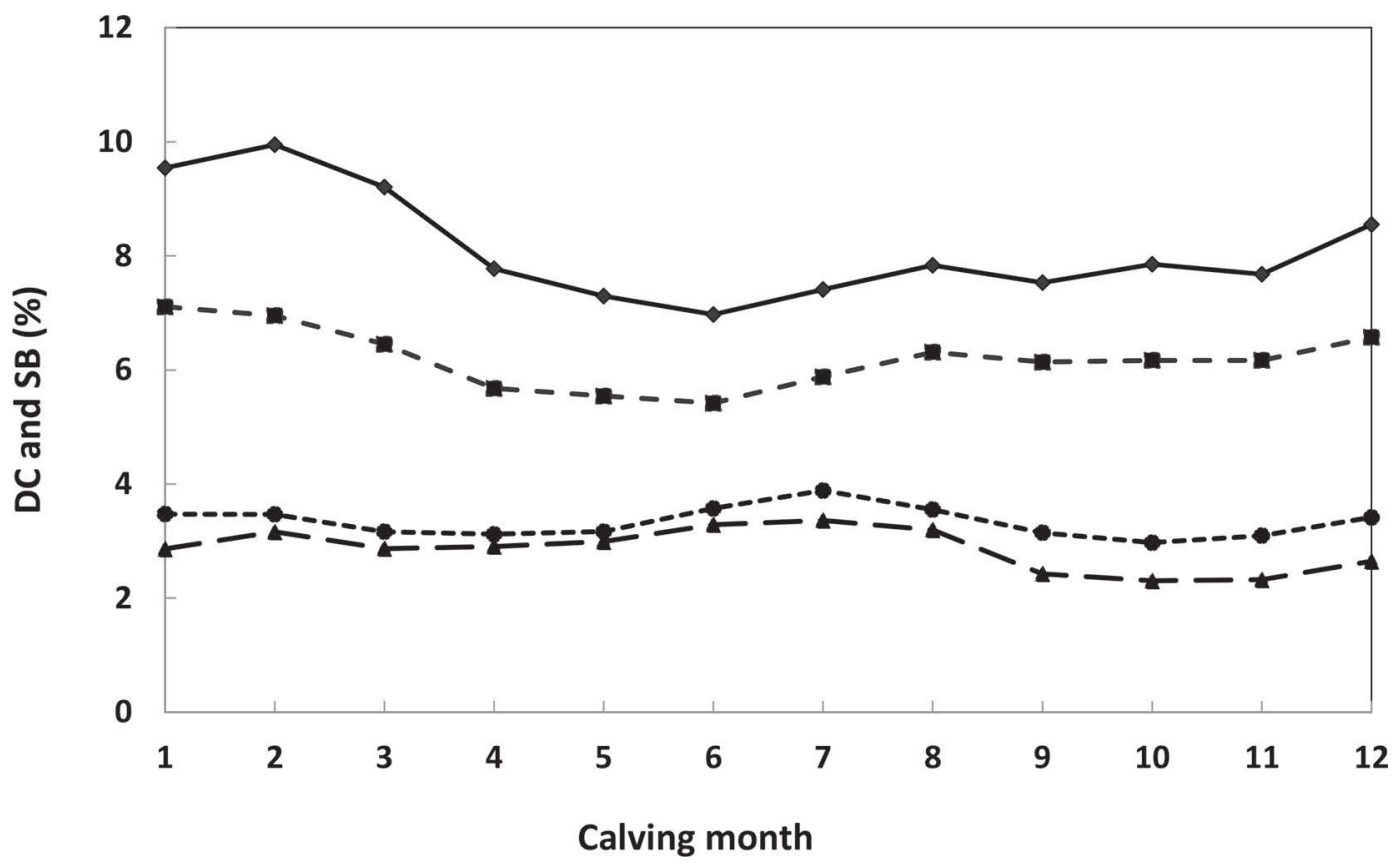

Figure 2. Effects of dystocia (DC) and stillbirth (SB) on parities 1 and 2 by calving month. $\bullet=$ dystocia first parity; $\mathbf{\square}=$ stillbirth first parity, $\boldsymbol{\Delta}=$ dystocia second parity; $\bullet=$ stillbirth second parity.

calves per sire, are given in Figure 7. Phenotypic, additive genetic, SC, and environmental trends are given in Table 6. Phenotypic trends from 1985 through 2015 were positive (i.e., economically unfavorable) for DC in both parities, but negative for SB. Genetic trends were economically unfavorable for both DC and SB in first parity. The SC trends were unfavorable for dystocia in both parities, favorable for stillbirth in first parity, and zero for second parity SB. Despite the positive genetic trends, first-parity DC peaked for cows born in 2007. The reduction in the first-parity cow effects since 2007 may be due to the fact that the SC effects for firstparity DC and SB were added to the Israeli selection index in 2006 (Weller and Ezra, 2006). In the previous analysis of the Israeli Holstein population for cows calving between 1978 and 1985, annual phenotypic trends were $0.33 \%$ and $-0.157 \%$ for DC and SB. respectively (Weller and Gianola, 1989). The environmental trends for all traits were nearly zero. Liu et al. (2012) found slightly positive genetic trends for both traits for both the cow and SC effects, but considered only 12 yr. Van Pelt and De Jung (2011) found positive genetic trends for SB for the cow effect and negative genetic trends for the SC effect from 1990 through 2010.

Standard deviations and correlations among 581,325 model 4 cow EBV with records for both parities are given in Table 7 . These values can be compared with the genetic correlations given in Table 3. Generally, the correlations among the EBV were higher than the genetic correlations, even though only cows with records on both traits were included. It should be noted that the model 1 genetic correlations refer to unrelated animals and correlations among EBV include the effects of relationships.

Standard deviations and correlations among the model 3 and 4 EBV of 1,443 sires of cow with model 3 reliabilities for $\mathrm{DC}>0.3$ are given in Table 8 , and SD and correlations among the model 3 and 4 SC EBV

Table 5. Phenotypic means and sex effects for first- and second-parity dystocia and still birth from the model 4 analysis

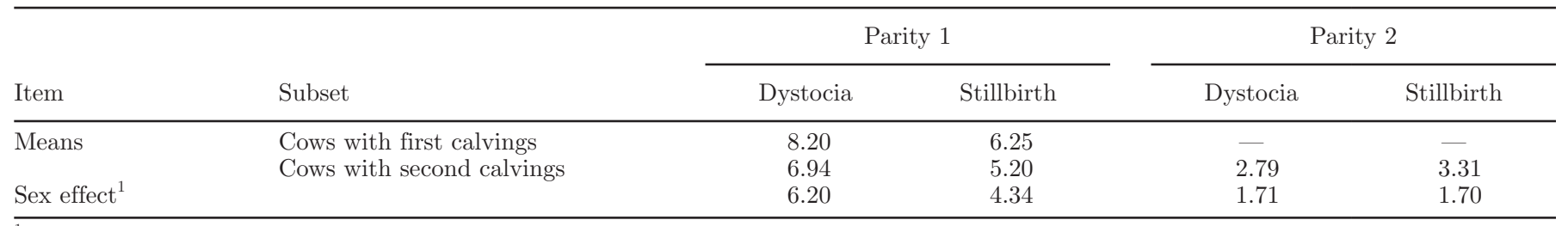

\footnotetext{
${ }^{1}$ Male-female effect.
} 


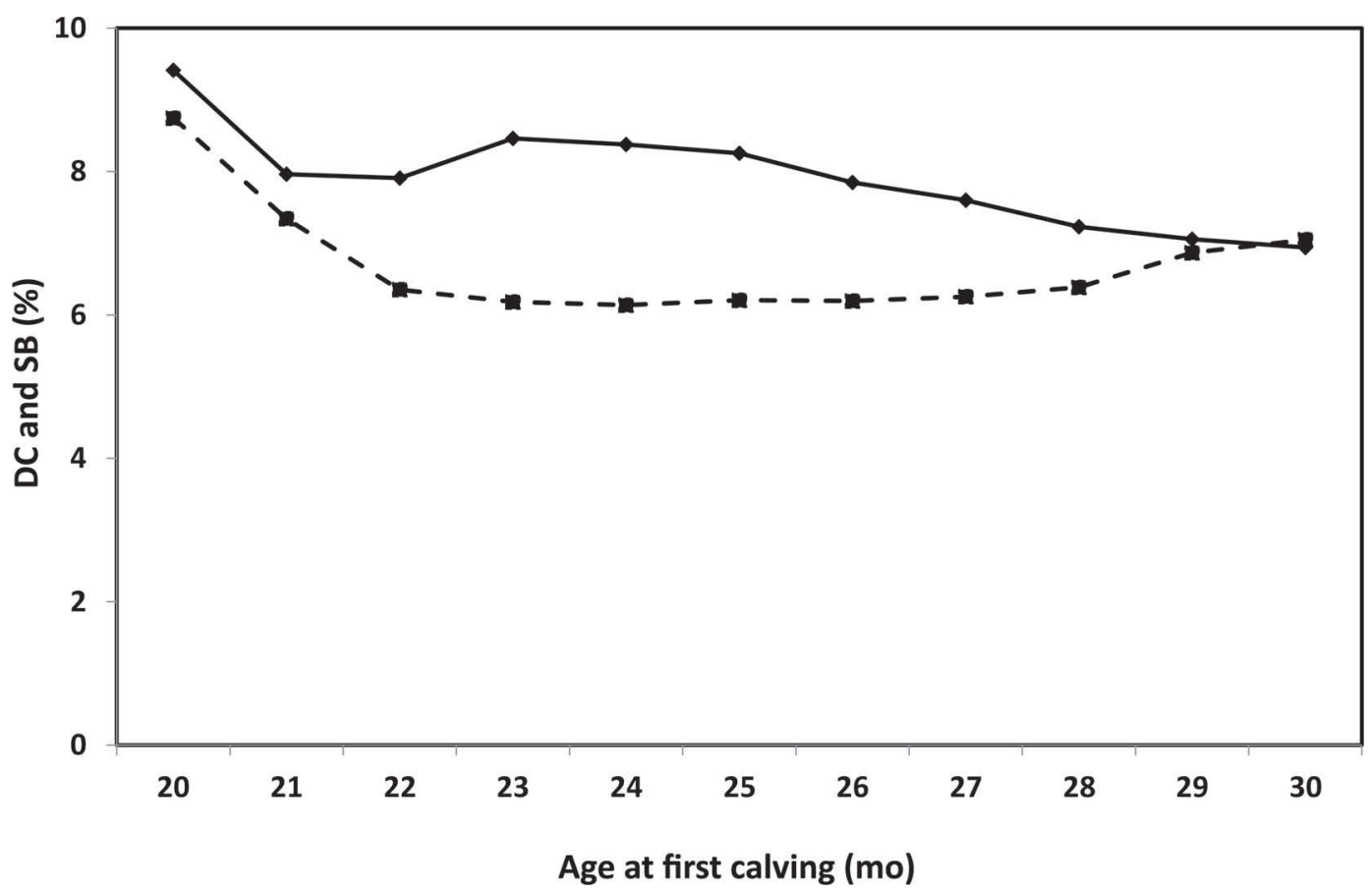

Figure 3. Means of dystocia (DC; $\bullet$ ) and stillbirth (SB; $\mathbf{a}$ ) in first parity by calving age.

for 471 bulls with model 3 reliabilities for $\mathrm{DC}>0.3$ for the cows given in the Table 7, which are based only are given in Table 9. As expected, the SD for the EBV on a single record for each of the 4 traits. Standard sires of cows in both models were higher than the SD deviations of the model 3 evaluations for sires of cows,

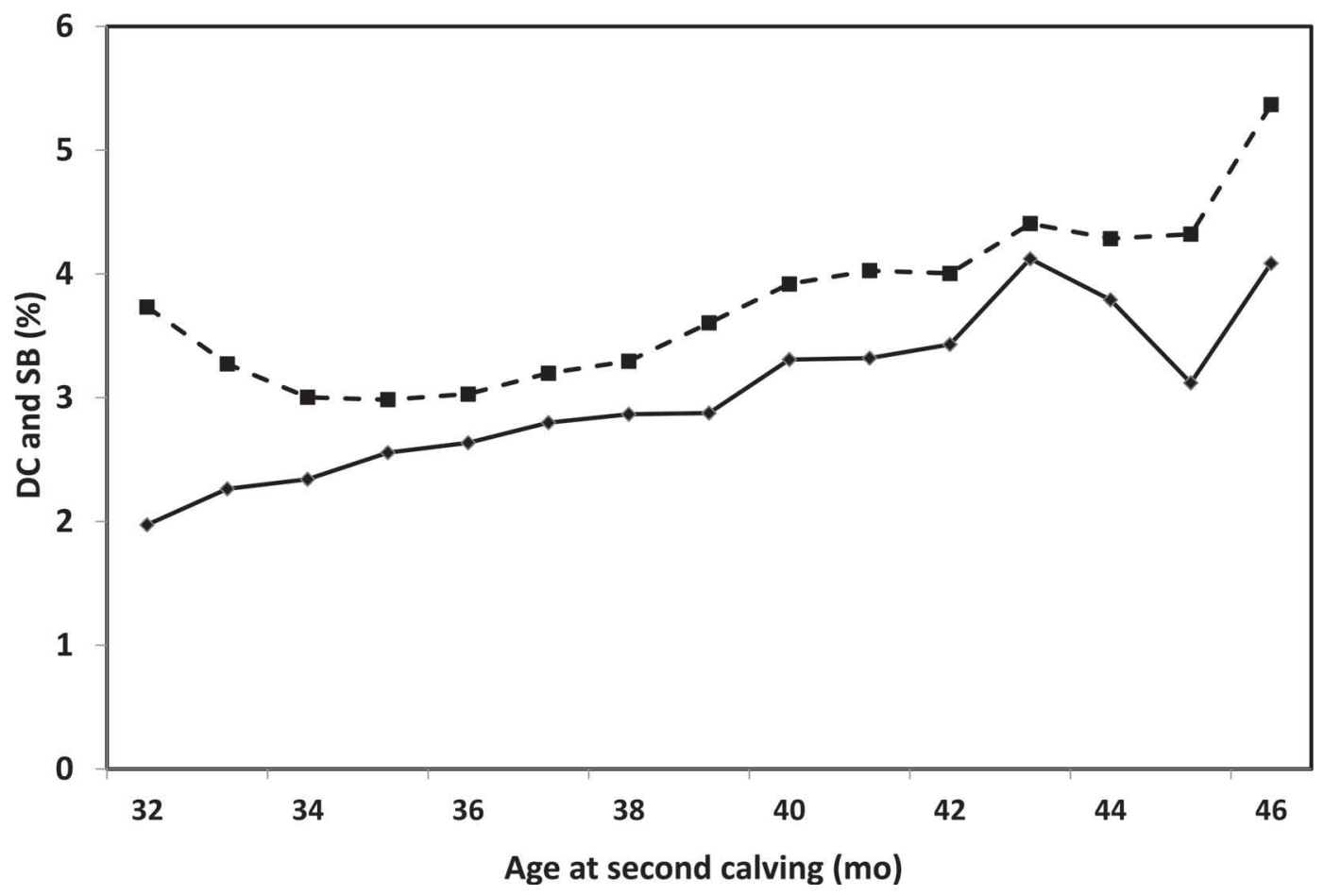

Figure 4. Means of dystocia (DC; $)$ and stillbirth (SB; $\boldsymbol{\square})$ in second parity by calving age. 


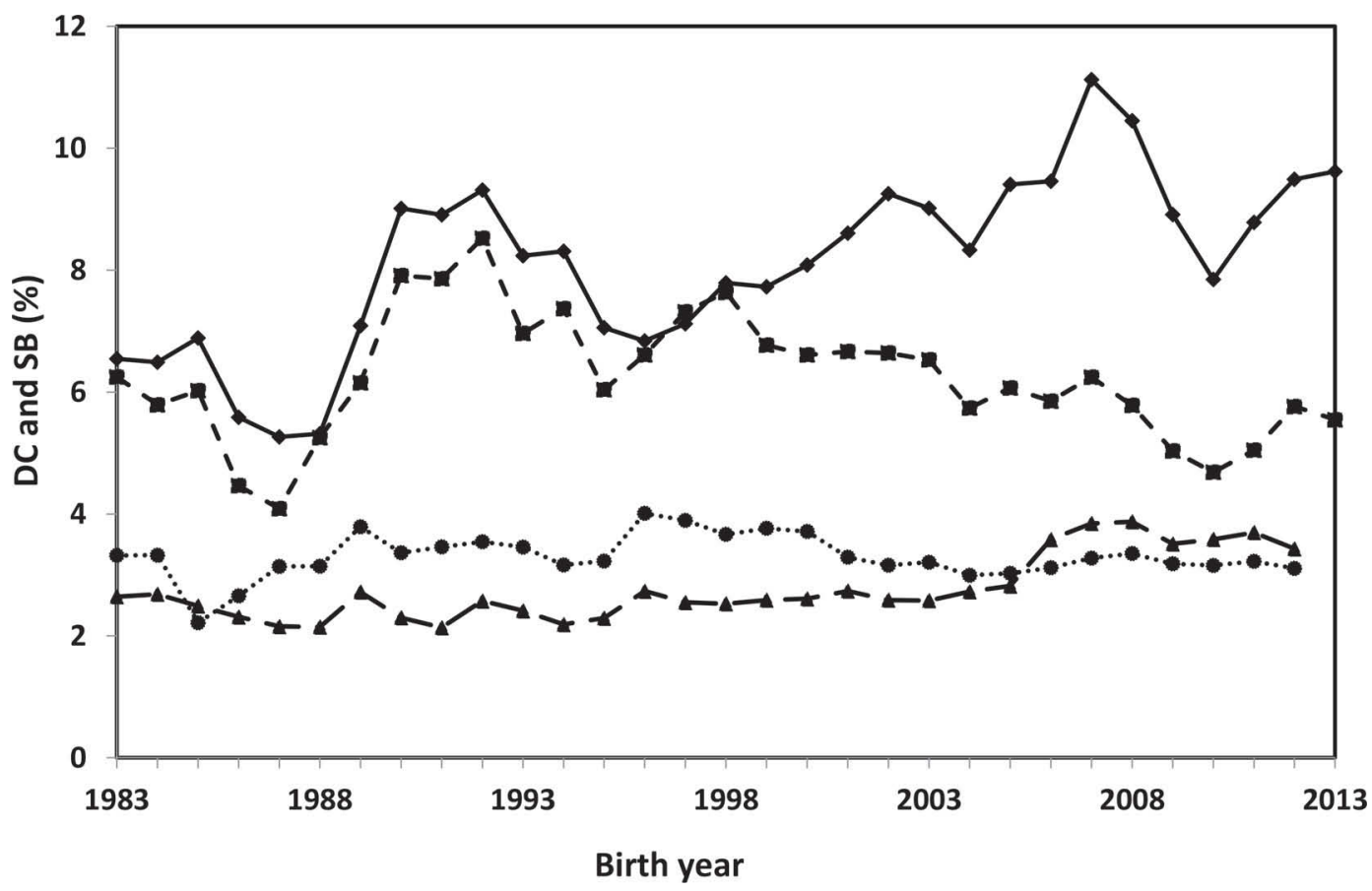

Figure 5. Means of dystocia (DC) and stillbirth (SB) in parities 1 and 2 by birth year. $\bullet=$ dystocia first parity; $\mathbf{\square}=$ stillbirth first parity; $\boldsymbol{\Delta}=$ dystocia second parity; $\bullet=$ stillbirth second parity.

computed from a sire-MGS model were multiplied by 2 of each sire. Standard deviations were higher for model to make them comparable to the model 4 evaluations, 3, even though model 4 accounts for relationships and which are computed on the scale of the breeding value correlations among the traits. For SC, the SD of the 2

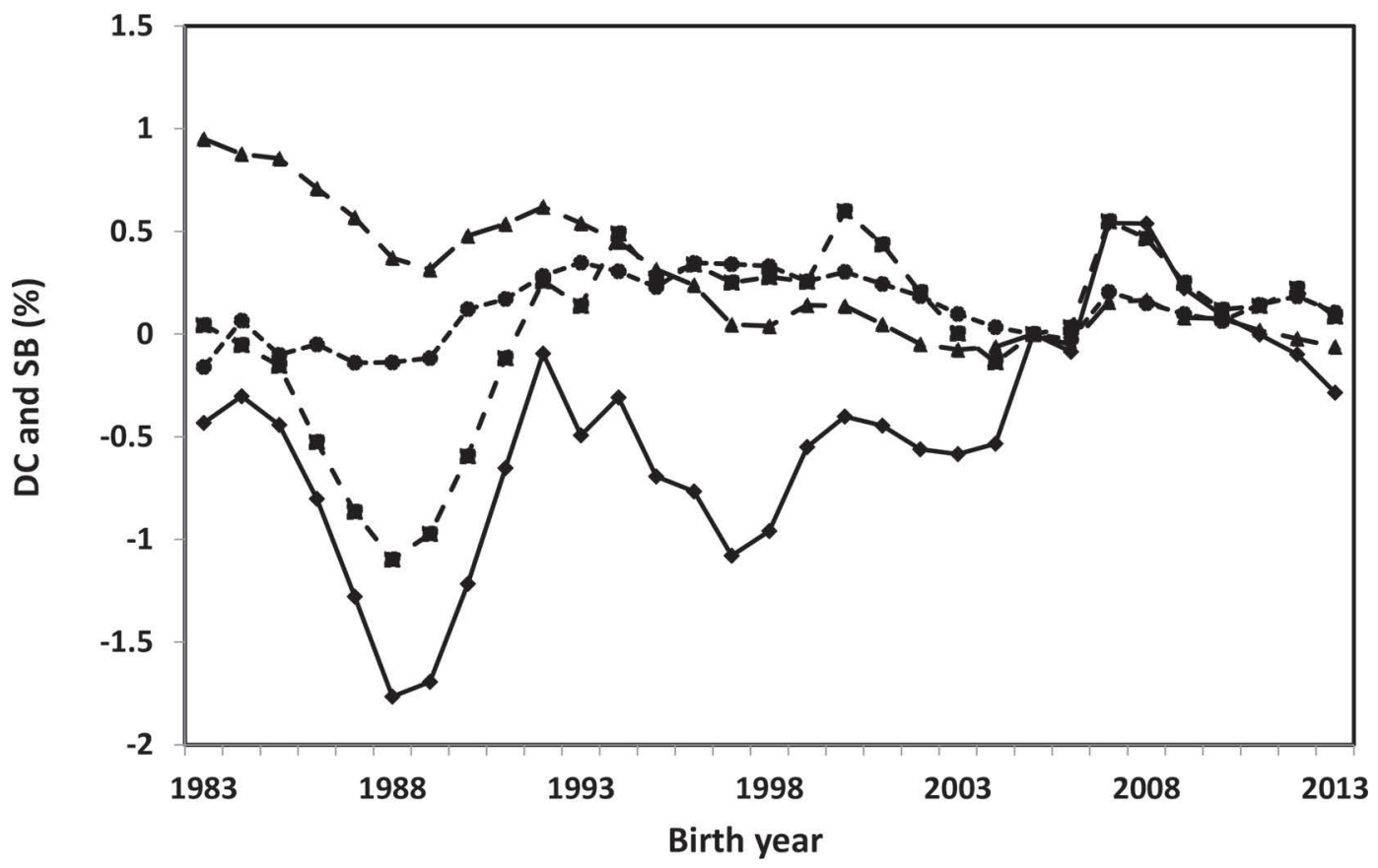

Figure 6. Mean EBV for first- and second-parity dystocia (DC) and stillbirth (SB) by birth year. $\bullet=$ dystocia first parity; $\mathbf{\square}=$ stillbirth first parity; $\boldsymbol{\Delta}=$ dystocia second parity; $\bullet=$ stillbirth second parity. 
Table 6. Phenotypic, genetic, calf of sire effect, and residual regressions in percent on birth year for first- and second-parity dystocia and stillbirth ${ }^{1}$

\begin{tabular}{lrrrrr}
\hline & \multicolumn{2}{c}{ Parity 1} & & \multicolumn{2}{c}{ Parity 2} \\
\cline { 2 - 3 } \cline { 5 - 6 } Trend & Dystocia & Stillbirth & & Dystocia & Stillbirth \\
\hline Phenotypic & 0.114 & -0.023 & & 0.041 & -0.006 \\
Genetic & 0.040 & 0.024 & & -0.029 & 0.004 \\
Sire of calf & 0.082 & -0.047 & & 0.068 & 0.000 \\
Environmental & -0.008 & 0.000 & & 0.002 & -0.010 \\
\hline
\end{tabular}

${ }^{1}$ All regressions were significant at $P<0.001$.

models were nearly equal for DC, but the model $4 \mathrm{SD}$ was higher for CM. Correlations between the 2 models for first-parity EBV of sires of cows were 0.84 and 0.80 ; for SC EBV, the corresponding correlations were 0.92 and 0.88 . These correlations can be considered moderately low for analysis of the same data by 2 different methodologies. All the sire of cow correlations among model 4 EBV were higher than the genetic correlations presented in Table 3 and similar to the cow EBV correlations in Table 7 , even though the cow correlations included only cows with records on both traits. The correlations among the model $4 \mathrm{SC}$ EBV were generally slightly lower than the $\mathrm{SC}$ genetic correlations presented in Table 4, as expected for animals with moderate reliabilities. Thus, the correlations given in Table 4 appear to accurately reflect reality, even though the analysis was based on a problematic sample, as noted previously.

Means and SD for model 3 and 4 reliabilities of 1,443 sires of cow EBV with model 3 reliabilities for DC $>0.3$ and correlations between the parity 1 reliabilities and given in Table 10. Means and SD for model 3 and 4 reliabilities of $471 \mathrm{SC}$ EBV with model 3 reliabilities for $\mathrm{DC}>0.3$ and correlations between the first-parity reliabilities are given in Table 11. For both sire of cow and SC, model 4 mean reliabilities were higher than the corresponding model 3 reliabilities. Among the model 4 reliabilities, mean reliabilities were higher for DC than for SB and higher for parity 1 than for parity 2 . For sire of cow and SC, correlations between the model 3 and 4 reliabilities were all close to 0.99 .
Means, SD, mean reliabilities, correlations of model 4 and $5 \mathrm{EBV}$, and regressions of model 4 on model 5 EBV for bulls born since 2005 are given in Table 12 . For the SC EBV, only bulls with model 5 reliabilities for DC in parity $1>0.65$ were included; 70 bulls met this criterion. For sire of cow, the criterion was set at reliabilities $>0.5$ because only 22 bulls met the criterion of reliability $>0.65 ; 91$ bulls met the lower criterion. Mixed model theory predicts that reliabilities and SD should be higher for the model 4 evaluations, which are based on more data. As expected, the model 4 mean reliabilities were slightly higher than the model 5 mean reliabilities for all traits for both effects. For the SC EBV for SB on parity 2, both reliabilities were $\sim 30 \%$; SD were very similar for both methods. All correlations and regressions were $>0.8$. Means of model $4 \mathrm{EBV}$ were lower for sire of cow evaluations, but higher for the first parity SC EBV. The EBV can be considered unbiased if the regression of the true genetic values on the EBV is not significantly different from zero and the y-intercept is not significantly different from zero. Although the model 4 evaluations should be more accurate than the model 5 evaluations, they are still not actual genetic values. Thus, it is not surprising the most of the second calving regressions were significantly different from unity.

The $\beta$ and $\delta$ coefficients for the Method 3 validation of the MAM evaluations and $0.02 \times \sigma_{g}$ values are given in Table 13. Except for the SC effect on SB in parity 1, the absolute value of $\delta>0.02 \times \sigma_{\mathrm{g}}$; however, as noted previously, this criterion was originally proposed for

Table 7. Standard deviations and correlations among model 4 estimated breeding values for 581,325 cows with records on both parities

\begin{tabular}{|c|c|c|c|c|c|}
\hline \multirow[b]{3}{*}{ Parity } & \multirow[b]{3}{*}{ Trait } & \multirow[b]{3}{*}{$\mathrm{SD}$} & \multicolumn{3}{|c|}{ Correlations } \\
\hline & & & \multirow{2}{*}{$\begin{array}{l}\text { Parity } 1 \\
\text { Stillbirth }\end{array}$} & \multicolumn{2}{|c|}{ Parity 2} \\
\hline & & & & Dystocia & Stillbirth \\
\hline \multirow[t]{2}{*}{1} & Dystocia & 2.49 & 0.782 & 0.770 & 0.538 \\
\hline & Stillbirth & 1.74 & - & 0.527 & 0.810 \\
\hline \multirow[t]{2}{*}{2} & Dystocia & 0.80 & - & - & 0.436 \\
\hline & Stillbirth & 0.67 & & & - \\
\hline
\end{tabular}




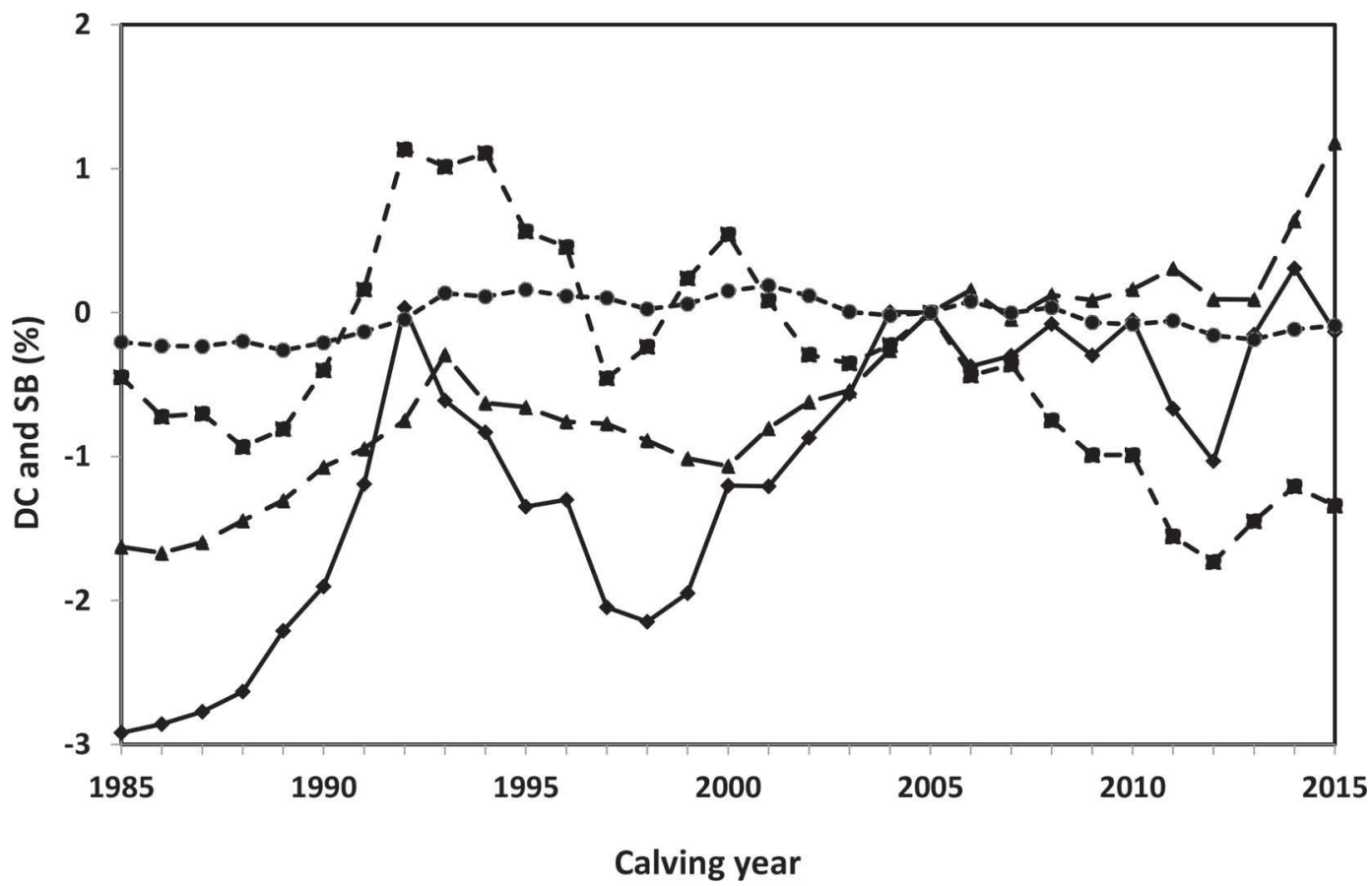

Figure 7. Mean estimated sire of calf effect for first- and second-parity dystocia (DC) and stillbirth (SB) by calving year. parity; $=$ stillbirth first parity; $\boldsymbol{\Lambda}=$ dystocia second parity; $\bullet=$ stillbirth second parity.

Table 8. Standard deviations and correlations among 1,443 sires of cow estimated breeding values with model 3 reliabilities for dystocia $>0.3$

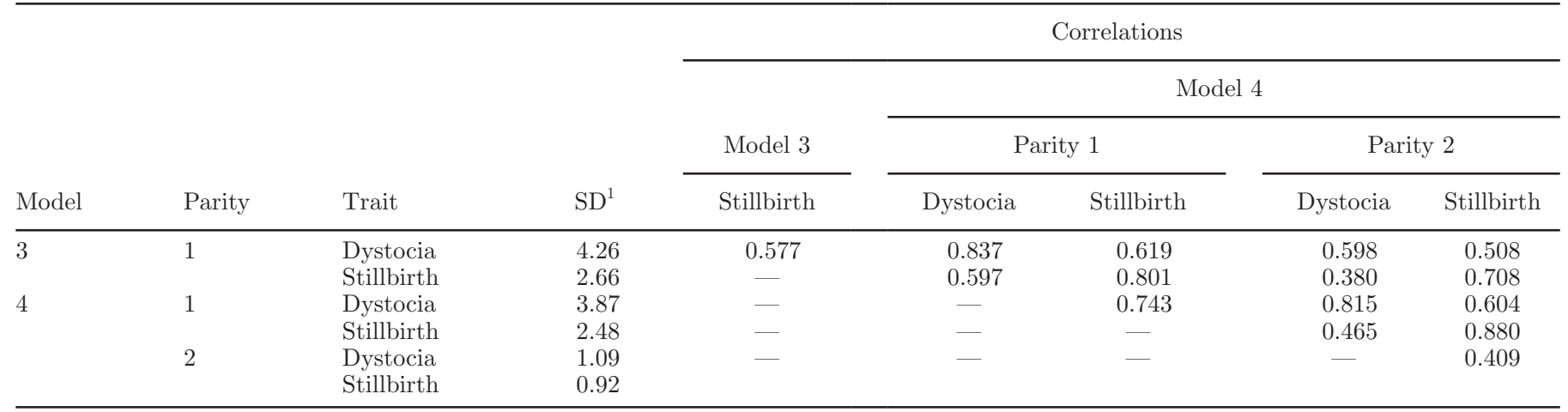

${ }^{1}$ Standard deviations of the Model 3 evaluations were multiplied by 2 to make them comparable to the Model 4 evaluations.

Table 9. Standard deviations and correlations among 471 sires of calf estimated breeding values with model 3 reliabilities for dystocia $>0.3$

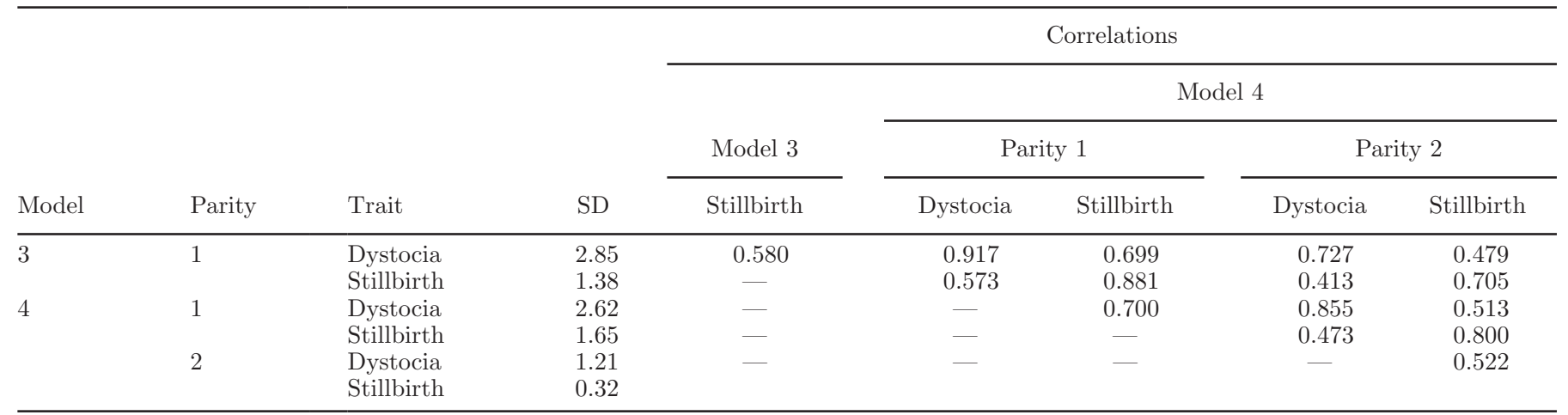


Table 10. Means and standard deviations for model 3 and 4 reliabilities of 1,443 sires of cow estimated breeding values with model 3 reliabilities for dystocia $>0.3$, and correlations between the first-parity reliabilities

\begin{tabular}{lllccc}
\hline Model & Parity & Trait & Means & SD & $\begin{array}{c}\text { Correlations, } \\
\text { models 3-4 }\end{array}$ \\
\hline 3 & 1 & Dystocia & 58.10 & 17.51 & 0.995 \\
4 & & Stillbirth & 47.58 & 19.93 & 0.988 \\
& \multirow{2}{*}{1} & Dystocia & 63.42 & 14.85 & \\
& \multirow{2}{*}{2} & Stillbirth & 51.13 & 16.57 & \\
& & Dystocia & 41.05 & 17.87 & \\
& & Stillbirth & 36.90 & 16.76 & \\
\hline
\end{tabular}

Table 11. Means and SD for model 3 and 4 reliabilities of 471 sires of calf estimated breeding values with model 3 reliabilities for dystocia $>0.3$, and correlations between the first-parity reliabilities

\begin{tabular}{lllccc}
\hline Model & Parity & Trait & Mean & SD & $\begin{array}{c}\text { Correlations, } \\
\text { models 3-4 }\end{array}$ \\
\hline 3 & 1 & Dystocia & 74.60 & 18.30 & 0.996 \\
& & Stillbirth & 55.55 & 26.40 & 0.996 \\
& \multirow{2}{*}{1} & Dystocia & 82.43 & 14.54 & \\
& \multirow{2}{*}{2} & Stillbirth & 73.25 & 19.18 & \\
& & Dystocia & 62.08 & 23.92 & \\
& Stillbirth & 31.65 & 7.66 & \\
\hline
\end{tabular}

Table 12. Means, standard deviations, mean reliabilities, correlations of model 4 and 5 evaluations, and regressions of model 4 on model 5 evaluations for bulls born since 2005

\begin{tabular}{|c|c|c|c|c|c|c|c|c|}
\hline \multirow[b]{2}{*}{ Effect } & \multirow[b]{2}{*}{ Parity } & \multirow[b]{2}{*}{ Trait } & \multicolumn{2}{|c|}{ Mean \pm SD } & \multicolumn{2}{|c|}{ Mean reliabilities } & \multirow[b]{2}{*}{ Correlation } & \multirow{2}{*}{$\frac{\text { Regression }}{\text { Model } 4 \text { on } 5}$} \\
\hline & & & Model 4 & Model 5 & Model 4 & Model 5 & & \\
\hline \multirow{2}{*}{$\begin{array}{l}\text { Sire of cow } \\
(\mathrm{n}=91)^{1}\end{array}$} & 2 & Dystocia & $0.14 \pm 1.12$ & $0.50 \pm 1.14$ & 40.9 & 32.1 & 0.83 & $0.82+0.06$ \\
\hline & & Stillbirth & $0.08 \pm 0.78$ & $0.37 \pm 0.72$ & 35.9 & 29.3 & 0.80 & $0.87+0.07$ \\
\hline \multirow{2}{*}{$\begin{array}{l}\text { Sire of calf } \\
(\mathrm{n}=70)^{2}\end{array}$} & 1 & Dystocia & $-0.07 \pm 2.27$ & $-0.44 \pm 2.26$ & 87.5 & 84.8 & 0.97 & $0.98+0.03$ \\
\hline & & Stillbirth & $-0.23 \pm 0.35$ & $-0.22 \pm 0.33$ & 31.3 & 29.1 & 0.96 & $1.02+0.04$ \\
\hline
\end{tabular}

${ }^{1}$ Reliabilities for first parity dystocia in model $5>0.5$.

${ }^{2}$ Reliabilities for first parity dystocia in model $5>0.65$.

Table 13. Beta and $\delta$ coefficients and their standard errors for the Method 3 validation of the model 4 evaluations

\begin{tabular}{|c|c|c|c|c|c|c|}
\hline Effect & $\begin{array}{l}\text { No. of } \\
\text { bulls }\end{array}$ & Parity & Trait & \multicolumn{3}{|c|}{ Coefficients $\pm \mathrm{SE}^{2}$} \\
\hline \multirow[t]{3}{*}{ Sire of cow } & 225 & 1 & Dystocia & $0.963 \pm 0.017$ & $-0.077 \pm 0.141$ & 0.009 \\
\hline & 229 & 2 & Dystocia & $0.989 \pm 0.021$ & $-0.066 \pm 0.052$ & 0.003 \\
\hline & & & Stillbirth & $0.979 \pm 0.016$ & $-0.004 \pm 0.044$ & 0.002 \\
\hline \multirow{2}{*}{ Sire of calf } & 74 & 1 & Dystocia & $0.971 \pm 0.019$ & $0.091 \pm 0.051$ & 0.014 \\
\hline & & & Stillbirth & $0.667 \pm 0.032$ & $-0.003 \pm 0.014$ & 0.001 \\
\hline
\end{tabular}

${ }^{1}$ Local bulls born between 2002 and 2006 were included in the analyses, except for sire of cow in second parity, in which bulls born between 2001 and 2005 were included.

${ }^{2}$ Standard errors were derived from Proc Reg of SAS (SAS Institute Inc., Cary, NC), which assumes a normal distribution of residuals.

${ }^{3} \sigma_{\mathrm{g}}$ is the genetic standard deviation. 
Table 14. Means and standard deviations of the model 4 and 5 evaluations for sire of calf and correlations between them for 17 bulls with $<5$ first-parity and $\geq 50$ second-parity calvings in 2011 and $\geq 40$ first-parity calvings in 2015

\begin{tabular}{llrrr}
\hline & & \multicolumn{2}{c}{ Mean \pm SD } & \\
\cline { 3 - 4 } Parity & Trait & Model 4 & Model 5 & $\begin{array}{c}\text { Correlation, } \\
\text { model 4 and } 5\end{array}$ \\
\hline 1 & Dystocia & $1.24 \pm 1.95$ & $-1.40 \pm 1.98$ & 0.610 \\
& Stillbirth & $-0.74 \pm 1.18$ & $-1.85 \pm 0.89$ & 0.119 \\
2 & Dystocia & $1.56 \pm 0.90$ & $0.94 \pm 0.90$ & 0.675 \\
& Stillbirth & $0.05 \pm 0.24$ & $-0.15 \pm 0.15$ & 0.165 \\
\hline
\end{tabular}

milk production traits, which have much higher heritabilities. None of the $\delta$ values were significantly different from zero $(P<0.05)$. Furthermore, the standard errors of the regression equation based on the assumption of a normal distribution of residuals are biased downwards for the $t_{i}$ effect, which has a highly skewed distribution (Weller et al., 2003). In conclusion, from the comparison of the model 4 and $5 \mathrm{EBV}$, no indication of significant bias was present in the evaluations.

Means and SD of the model 4 and 5 evaluations for sire of calf, as well as correlations between them for bulls with $<5$ first-parity and $\geq 50$ second-parity calvings in 2011 and $\geq 40$ first-parity calvings in 2015, are given in Table 14. As young bulls in Israel are generally mated to first-parity cows, the objective was to determine the ability of second-parity EBV derived from the first crop bull mates to predict first-parity EBV for the SC effect in the second crop of bull mates. In this case, the correlations among the first-parity EBV are of interest. These correlations were 0.61 and 0.12 for $\mathrm{DC}$ and $\mathrm{SB}$, even though the model $5 \mathrm{EBV}$ are based chiefly on second calving records. Thus, EBV of the $\mathrm{SC}$ effect based only on second-parity records are able to generate useful predictions for first-parity DC, but not for SB. In conclusion, model 4, which computes EBV for all animals for all 4 traits accounting for all known relationships and correlations among the traits, is recommended for routine genetic evaluation of calving traits.

\section{CONCLUSIONS}

Similar to previous studies, all heritabilities were quite low, but higher for DC than for SB and higher in first parity. The sire-of-calf heritabilities were higher than the cow effect heritabilities, except for SB in parity 2. Unlike the effect of cow genetic correlations, all sire of calf correlations were $>0.6$, and the correlations for the same trait in parities 1 and 2 were $>0.9$. Thus, the multi-trait analysis should yield a significant gain in accuracy with respect to the sire of calf effects. The $\mathrm{DC}$ in first parity was lowest for cows calving at $30 \mathrm{mo}$ of age. For parity 1, optimum first-parity calving age for SB was 23 to 27 mo. For parity 2, DC increased with increase in calving age up to 43 mo, whereas SB was minimal for cows calving at age of 35 mo. Correlations between the approximate reliabilities for the complete animal model analysis and reliabilities obtained by direct inversion of the coefficient matrix for a sire of cow-sire of calf model were all close to 0.99. Phenotypic trends from 1983 through 2007 were positive (i.e., economically unfavorable) for DC and slightly negative for SB in both parities. Genetic trends were economically unfavorable for both DC and SB in first parity. Firstparity sire of calf trends were unfavorable for DC but favorable for SB. All environmental trends were nearly zero. Regressions of EBV of the complete analysis on a model including only calvings before 2012 were all $>0.8$. All traits met the Interbull Method 3 criterion for unbiasedness; thus, no indication of significant bias was observed in the evaluations. The EBV of the SC effect based only on second-parity records are able to generate useful predictions for first-parity DC, but not for SB. The proposed multi-trait individual animal model is recommended for routine genetic evaluation of calving traits.

\section{ACKNOWLEDGMENTS}

This research was supported by grants from the Israel Dairy Board (Yahud, Israel). We thank I. Misztal (University of Georgia, Athens) for use of the MTC and CMMAT programs.

\section{REFERENCES}

Bar-Anan, R., M. Soller, and J. C. Bowman. 1976. Genetic and environmental factors affecting the incidence of difficult calving and perinatal calf mortality in Israeli Friesian dairy herds. Anim. Prod. 22:299-310.

Berger, P. J. 1994. Genetic prediction for calving ease in the United States: Data, models, and use by the dairy industry. J. Dairy Sci. 77:1146-1153.

Boelling, D., U. Sander Nielsen, J. Pösö, J.-A. Eriksson, and G. P. Aamand. 2007. Genetic evaluation of calving traits in Denmark, Finland and Sweden. Interbull Bull. 37:179-184. 
Boichard, D., B. Bonaiti, A. Barbat, and S. Mattalia. 1995. Three methods to validate the estimation of genetic trend for dairy cattle. J. Dairy Sci. 78:431-437.

Cole, J. B., G. R. Wiggans, and P. M. VanRaden. 2007a. Genetic evaluation of stillbirth in United States Holsteins using a sire maternal grandsire threshold model. J. Dairy Sci. 90:2480-2488.

Cole, J. B., G. R. Wiggans, P. M. VanRaden, and R. H. Miller. 2007b. Stillbirth (co)variance components for a sire-maternal grandsire threshold model and development of a calving ability index for sire selection. J. Dairy Sci. 90:2489-2496.

Cue, R. I., and J. F. Hayes. 1985. Correlations between calving ease and calf survival. J. Dairy Sci. 68:958-962.

Djemali, M., P. J. Berger, and A. E. Freeman. 1987. Ordered categorical sire evaluation for dystocia in Holsteins. J. Dairy Sci. 70:2374-2384.

Jamrozik, J., J. Fatehi, G. J. Kistemaker, and L. R. Schaeffer. 2005. Estimates of genetic parameters for Canadian Holstein female reproduction traits. J. Dairy Sci. 88:2199-2208.

Klassen, D. J., R. I. Cue, and J. F. Hayes. 1990. Estimation of repeatability of calving ease in Canadian Holsteins. J. Dairy Sci 73:205-212.

Liu, Z., E. Pasman, F. Reinhardt, and R. Reents. 2012. A multi-parity animal model for genetic evaluation of calving traits enhanced with genomic information. Interbull Bull. 46:133-140.

Misztal, I., and G. R. Wiggans. 1988. Approximation of prediction error variance in large-scale animal models. J. Dairy Sci. 71(Suppl. 2):27.

Robinson, G. K. 1986. Group effects and computing strategies for models for estimating breeding values. J. Dairy Sci. 69:3106-3111.

Ron, M., R. Bar-Anan, and J. I. Weller. 1986. Sire and maternal grandsire effects on calving difficulty and calf mortality in Israeli Holsteins. J. Dairy Sci. 69:243-247.
Van Pelt, M. L., and G. De Jung. 2011. Genetic evaluation for direct and maternal livability in The Netherlands. Interbull Bull. 44:65-70.

Van Tassell, C. P., G. R. Wiggans, and I. Misztal. 2003. Implementation of a sire-maternal grandsire model for evaluation of calving ease in the United States. J. Dairy Sci. 86:3366-3373.

Weller, J. I., U. Emanuelson, and E. Ezra. 2003. Validation of genetic evaluation methodology using the nonparametric bootstrap method. Pages 26-29 in Proc. 2003 Interbull Meeting. Rome, Italy, vol. 31. Interbull, Uppsala, Sweden.

Weller, J. I., and E. Ezra. 2006. Difficult calving and calf mortality in the breeding index. Meshek Habakar Vehahalav 325:53-55. (In Hebrew).

Weller, J. I., and E. Ezra. 2015. Environmental and genetic factors affecting cow survival of Israeli Holsteins. J. Dairy Sci. 98:676-684

Weller, J. I., and D. Gianola. 1989. Models for genetic analysis of dystocia and calf mortality. J. Dairy Sci. 72:2633-2643.

Weller, J. I., I. Misztal, and D. Gianola. 1988. Genetic analysis of dystocia and calf mortality in Israeli-Holsteins by threshold and linear models. J. Dairy Sci. 71:2491-2501.

Westell, R. A., and L. D. Van Vleck. 1987. Simultaneous genetic evaluation of sires and cows for a large population of dairy cattle. J. Dairy Sci. 70:1006-1017.

Wiggans, G. R., J. B. Cole, and L. L. M. Thornton. 2008. Multiparity evaluation of calving ease and stillbirth with separate genetic effects by parity. J. Dairy Sci. 91:3173-3178.

Wiggans, G. R., I. Misztal, and C. P. Van Tassell. 2003. Calving ease (co)variance components for a sire-maternal grandsire threshold model. J. Dairy Sci. 86:1845-1848.

Wiggans, G. R., I. Misztal, and L. D. Van Vleck. 1988. Implementation of an animal model for genetic evaluation of dairy cattle in the United States. J. Dairy Sci. 71:54-69. 